\title{
COMUNICAÇÃO
}

\section{REGENERAÇÃO DE Euphorbia heterophylla L. IN VITRO}

\author{
In vitro regeneration of Euphorbia heterophylla $\mathrm{L}$.
}

\author{
Francieli Colussi ${ }^{1}$, Audrei Nisio Gebieluca Dabul ${ }^{2}$, Ricardo Antonio Ayub ${ }^{3}$
}

\begin{abstract}
RESUMO
Objetivou-se neste trabalho estudar a regeneração in vitro da planta daninha Euphorbia heterophylla a partir de explantes hipocotiledonares, cotiledonares e radiculares com diferentes concentrações do hormônio $2 \mathrm{iP}$, combinado ou não com auxina e cinetina adicionado ao meio MS/2. Foram avaliados os números de explantes com gema, número de gemas por explante, número de plântulas enraizadas e aclimatadas. Obteve-se em média duas gemas por explante hipocotiledonar em 50\% desses, a partir de organogênese direta com o uso de $0,5 \mathrm{mg} . \mathrm{L}^{-1} \mathrm{de} 2 \mathrm{iP}$. Não houve regeneração a partir dos explantes cotiledonares e radiculares. A cultura racinar desenvolveu-se em todos os tratamentos contendo ou não auxina. Esses resultados poderão auxiliar em futuros testes fisiológicos de resistência dessa planta a herbicidas.
\end{abstract}

Termos para indexação: Leiteiro, organogênese, morfogênese.

\section{ABSTRACT}

This work aimed to study the in vitro regeneration of the weed Euphorbia heterophylla from hypocotyls, cotyledon and root explants grown under different concentrations of the hormone $2 \mathrm{iP}$, combined or not with auxin added to MS/2 medium. The parameters analyzed were the number of explants with shoot, number of shoot for explants, number of rooted and acclimatized plants. The results showed an average of two shoot for hypocotyls explants, in 50\% of these, from direct organogenesis with the use of $0.5 \mathrm{mg}$. . ${ }^{-1}$ of $2 \mathrm{iP}$. No regeneration from the cotyledon and root explants was verified. The root culture developed in all treatments with or without auxin. These results will be able to assist in future physiological tests of resistance of this plant of herbicides.

Index terms: Wild poinsettia, organogenesis, morphogenesis.

\section{(Recebido em 18 julho de 2006 e aprovado em 2 de abril de 2007)}

Euphorbia heterophylla L., conhecida como leiteiro é uma planta de morfologia muito variável e uma das mais temidas espécies infestantes, principalmente nas regiões tropicais e subtropicais das Américas (CRONQUIST, 1981). Essa espécie está amplamente distribuída no centro-sul do Brasil, contatando-se sua presença em $74 \%$ das áreas de soja do planalto do estado do Rio Grande do Sul (VIDAL \& WINKLER, 2002). Tem extraordinária capacidade de multiplicação e as plantas crescem com muita rapidez, e tendem a sombrear plantas de culturas anuais de desenvolvimento mais lento. Por isso competem intensamente na absorção de nutrientes do solo (KISSMAN \& GROTH, 1999), sendo de difícil controle e resistente à maioria dos herbicidas utilizados no combate às folhas largas (WILSON, 1981). Esse controle é realizado principalmente com herbicidas inibidores das enzimas acetolactato sintase (ALS) e protoporfirinogênio oxidase (PROTOX) (VIDAL \& MEROTTO JÚNIOR, 2001).
Além da importância agrícola, também tem-se buscado características farmacêuticas de Euphorbiaceae: a extração de substâncias bactericidas eficientes contra Escherichia coli e Bacillus subtilis, (DOROTHY et al., 2006); isolamento e caracterização parcial de lecitina em sementes (MAKUTA et al., 1983); levantamento fitoquímico e antiinflamatório de extratos aquosos e metanólicos (FALODUN et al., 2006) utilizado para tratamentos de asma, bronquite e constipação; e testes com ratos vêm demonstrando a atividade analgésica das raízes de leiteiro (VAMSIDHARA, 2000).

A obtenção de explantes in vitro de leiteiro (COLUSSI \& AYUB, 2003) pode contribuir com estudos fisiológicos na agricultura e na farmacologia. Com o objetivo de avaliar diferentes explantes e concentrações de reguladores vegetais na regeneração in vitro de leiteiro, buscou-se aumentar os conhecimentos em relação à morfogênese dessa planta. Os prejuízos financeiros à

\footnotetext{
Bióloga, Mestre - Departamento de Fitotecnia e Fitossanidade - Universidade Estadual de Ponta Grossa/UEPG - Avenida General Carlos Cavalcanti, 4748 - Campus Uvaranas - 84030-900 - Ponta Grossa, PR - francielicolussi@yahoo.com.br

Engenheiro Agrônomo - Departamento de Fitotecnia e Fitossanidade - Universidade Estadual de Ponta Grossa/UEPG - Avenida General Carlos Cavalcanti, 4748 - Campus Uvaranas - 84030-900 - Ponta Grossa, PR - agdabul@yahoo.com.br

${ }^{3}$ Engenheiro Agrônomo, Doutor, Professor - Departamento de Fitotecnia e Fitossanidade - Universidade Estadual de Ponta Grossa/UEPG - Avenida General Carlos Cavalcanti, 4748 - Campus Uvaranas - 84030-900 - Ponta Grossa, PR - rayub@uepg.br
} 
agricultura e seu alto valor agregado medicinal merecem destaque.

Sementes de E. heterophylla foram coletadas em lavouras de soja da região sudoeste do Paraná, no ano de 2004, e armazenadas em ambiente refrigerado e germinadas conforme Colussi \& Ayub (2003).

Plântulas de sete dias de idade, a partir da emissão da radícula, foram utilizadas como fontes de explantes cotiledonares, hipocotiledonares e radiculares. Os explantes cotiledonares foram seccionados em seis partes, explantes hipocotiledonares e radiculares excisados com um $\mathrm{cm}$ de comprimento e colocados em meio nutritivo básico MS (MURASHIGE \& SKOOG, 1962), contendo metade das concentrações de sais e vitaminas, acrescido de $30 \mathrm{~g} / \mathrm{L}$ de sacarose, preparado por dissolução dos componentes em água destilada. $\mathrm{O} \mathrm{pH}$ foi ajustado para 5,6 com $\mathrm{NaOH}$ 0,1N e solidificado com $6 \mathrm{~g} / \mathrm{L}$ de ágar $\left(\right.$ Sigma $\left.^{\circledR}\right)$. Os meios suplementados com diferentes concentrações e combinações de reguladores de crescimento constituem os tratamentos descritos a seguir para todos os explantes: 0,5mg/L 2iP (T1); 0,5mg/L 2iP + 0,1mg/L AIA (T2); 1,0mg/L 2iP+0,1mg/L AIA (T3); 1,5mg/L $2 \mathrm{iP}+0,1 \mathrm{mg} / \mathrm{L}$ AIA (T4). As culturas inoculadas foram mantidas em condições controladas a $25^{\circ} \mathrm{C}$ e $16 \mathrm{~h}$ de fotoperíodo, e 2600 lux.

Após 30 dias de cultivo, os brotos foram individualizados e transferidos para o meio de enraizamento $\mathrm{MS} / 2$, sem reguladores de crescimento. As plantas enraizadas foram acondicionadas em copos plásticos com terra autoclavada para aclimatação (Figura 1 F e G).

Pode-se observar que o efeito das diferentes combinações de reguladores de crescimento acondicionados no meio $\mathrm{MS} / 2$ de E. heterophylla não regeneraram gemas a partir de explantes cotiledonares e radiculares, em nenhum dos tratamentos testados (dados não demonstrados).

Os explantes hipocotiledonares desenvolveram brotações (Figura 1A e B) no meio MS/2 suplementado com $0,5 \mathrm{mg} . \mathrm{L}^{-1}$ de $2 \mathrm{iP}$ (Tabela 1 ). Os resultados evidenciaram um processo de morfogênese do tipo organogênese direta, sem a formação de calos (Figura 1A). Aproximadamente cinqüenta por cento dos explantes hipocotiledonares regeneraram duas gemas, em média. Gemas que após seu alongamento foram enraizadas e aclimatadas em casa-de-vegetação (Figura 1 D e E). Esse resultado de organogênese direta se diferencia dos testes feitos por Prasad \& Satyasree (1994), que tiveram a organogênese indireta de E. heterophylla, na presença da auxina ANA.

Tratamentos com AIA foram eficientes na formação de raízes para os explantes radiculares (Figura 1C) e hipocotiledonares o que confirma os resultados obtidos por Prasad \& Satyasree (1994). Entretanto o enraizamento ocorre na ausência de ANA (Figura 1E). A formação de raízes adventícias apenas com os níveis endógenos de auxina, que é o caso da E. heterophylla, também ocorre no maracujá (RIBAS, 2000).

Os brotos regenerados não apresentaram deformações morfológicas como hiperhidricidade (ZIV, 1995), indicando que não houve efeito prejudicial dos reguladores de crescimento sobre os brotos regenerados (CURY \& CASSELLS, 2001), dos nutrientes, nem do conteúdo do ágar sobre a morfogênese (SAHER et al., 2004).

As diferenças quanto à regeneração entre os diferentes explantes testados poderiam ser explicadas pelo gradiente interno de reguladores de crescimento, pelo grau de determinação dos tecidos, para responder a estímulos hormonais (TRAN THANH VAN, 1973). A alta capacidade

Tabela 1 - Avaliação de diferentes concentrações do regulador de crescimento 2IP, com ou sem AIA, na regeneração de explantes hipocotiledonares de leiteiro.

\begin{tabular}{|c|c|c|c|c|c|c|}
\hline Tratamento & $\begin{array}{c}\mathrm{N}^{\mathbf{o}} \\
\text { explantes }\end{array}$ & $\begin{array}{c}\mathrm{N}^{\mathrm{o}} \\
\text { explante/gema }\end{array}$ & $\begin{array}{c}\mathrm{N}^{\circ} \text { Gemas / } \\
\text { explante (média) }\end{array}$ & $\begin{array}{c}\mathrm{N}^{\mathrm{o}} \\
\text { Brotos }\end{array}$ & Enraizadas & Aclimatadas \\
\hline $0,5 \mathrm{mg} / \mathrm{L} 2 \mathrm{iP}$ & 30 & 14 & 2 & 28 & 10 & 10 \\
\hline $\begin{array}{l}0,5 \mathrm{mg} / \mathrm{L} 2 \mathrm{iP}+ \\
0,1 \mathrm{mg} / \mathrm{L} \text { AIA }\end{array}$ & 30 & 0 & 0 & 0 & 0 & 0 \\
\hline $\begin{array}{l}1,0 \mathrm{mg} / \mathrm{L} 2 \mathrm{iP}+ \\
0,1 \mathrm{mg} / \mathrm{L} \text { AIA }\end{array}$ & 30 & 0 & 0 & 0 & 0 & 0 \\
\hline $\begin{array}{l}1,5 \mathrm{mg} / \mathrm{L} 2 \mathrm{iP}+ \\
0,1 \mathrm{mg} / \mathrm{L} \text { AIA }\end{array}$ & 30 & 0 & 0 & 0 & 0 & 0 \\
\hline
\end{tabular}


de regeneração dos explantes jovens é explicada pela maior atividade metabólica e uma adequada concentração hormonal endógena (SKOOG \& MILLER, 1957), como resultado de um equilíbrio entre as concentrações internas e as supridas externamente com o meio, além de uma interação com os nutrientes (RAMAGE \& WILLIAMS, 2002).
A manutenção da umidade no plástico com a aspersão de gotículas de água (Figura 1F), foi essencial para o desenvolvimento e sobrevivência da plântula $e x$ vitro, onde $100 \%$ das plantas enraizadas foram aclimatadas (Figura G).

Estudos recentes com E. heterophylla têm demonstrado o grande potencial dessa planta como modelo
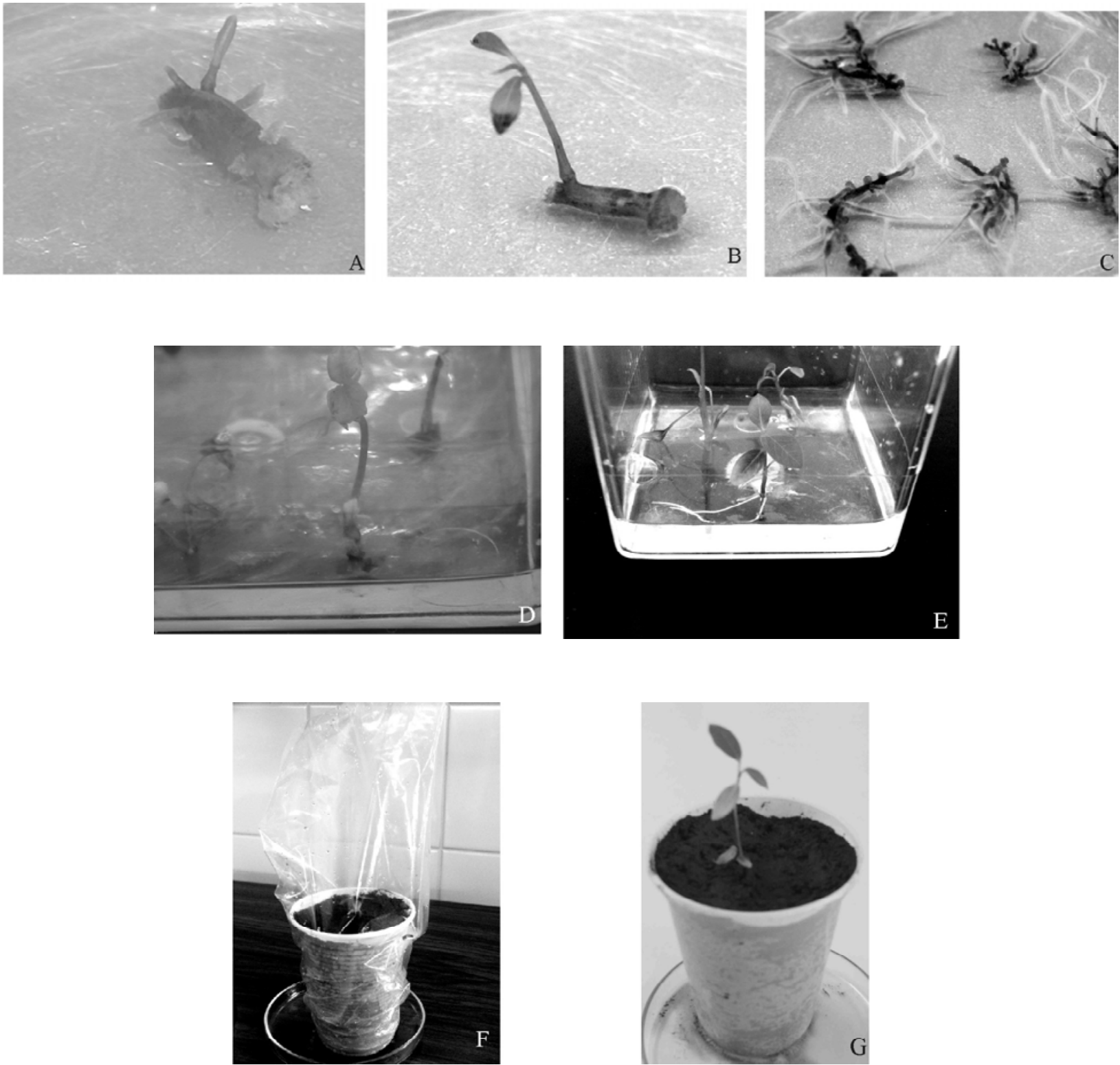

Figura 1 - (A-B) Organogênese a partir de explantes hipocotiledonares em meio MS/2. (C) Rizogênese a partir de explantes radiculares. (D) Enraizamento das plântulas em meio MS/2 sem hormônios. (E) Plântulas enraizadas (F)Aclimatização das plântulas com a proteção do plástico e $(\mathrm{G})$ após 10 dias aclimatizando em ambiente de laboratório. 
para trabalhos na área agrícola (GELMINI et al., 2001; VIDAL \& WINKLER, 2002) e farmacológica (DOROTHY et al., 2006; FALODUN et al., 2006) ainda pouco explorados, o que poderá fornecer subsídios para o manejo dessa planta daninha, bem como auxiliar na busca por novos princípios ativos.

A partir desta discussão podemos concluir que a regeneração de E. heterophylla é obtida a partir de explante hipocotiledonar em meio MS/2, suplementado com $0,5 \mathrm{mg} /$ L 2iP, onde se obteve 46,7\% de regeneração dos explantes contendo, em média, duas gemas. A cultura racinar é obtida a partir dos explantes radiculares e hipocotiledonares em meio com 2iP + AIA. Não foi possível obter nenhum tipo de regeneração com explantes cotiledonares.

\section{REFERÊNCIAS BIBLIOGRÁFICAS}

COLUSSI, F.; AYUB, R. A. Regeneração in vitro de Euphorbia heterophylla In: CONGRESSOBRASILEIRO DE FLORICULTURA E PLANTAS ORNAMENTAIS, 14.; CONGRESSO BRASILEIRO DECULTURADETECIDOS, 1., 2003, Lavras. Anais... Lavras: UFLA/FAEPE, 2003. p. 154.

CRONQUIST, A. An integrated system of classification of flowering plants. New York: Columbia University, 1981. $1262 \mathrm{p}$.

CURY, R.; CASSELLS, A. C. Oxidative stress and physiological, epigenetic and variability in plant tissue culture: implications for micropropagators and genetic engineers. Plant Cell, Tissue and Organ Culture, Netherlands, v. 64, n. 2/3, p. 145-157, Jan. 2001.

DOROTHY, W. S.; WEATHERWAX, P.; McCLUNG, L. S. Antibacterial substances from plants collected in Indiana. Botanical and Bacteriological Laboratories, Bloomington, v. 6, 2006.

FALODUN, A.; OKUNROBO, L. O.; UZOAMAKA, O. Phytochemical screening and anti-inflammatory evaluation of methanolic and aqueous extracts of Euphorbia heterophylla Linn (Euphorbiaceae). Academic Journals, 2006. Disponível em: <http://www.academicjournals.org/ AJB>. Acesso em: 20 maio 2006.

GELMINI, G. A.; VARELA FILHO, R.; SOARES-NOVO, M. C. S.; ADORYAN, M. L. Resistências de biótipos de Euphorbia heterophylla ao inibidores de enzima ALS utilizados na cultura de soja. Bragantia, Campinas, v. 60, n. 2, p. 93-99, 2001.
KISSMANN, K. G.; GROTH, D. Plantas infestantes e nocivas. São Paulo: Basf Brasileira, 1999. v. 2, 978 p.

MAKUTA, N. L.; WILLY, J. P.; ALBERT, R. C. Isolation and partial characterization of a lectin from Euphorbia heterophylla seeds. Biochemical Journal, Great Britain, v. 29, n. 215, p. 141-145, 1983.

MURASHIGE, T.; SKOOG, F. A revised medium for rapid growth and bioassays with tobacco tissue cultures. Physiologia Plantarum, Copenhagen, v. 15, n. 6, p. 473479, 1962.

PRASAD, M. N. V.; SATYASREE, J. G. Alpha-naphthalene acetic-acid regulated anthocyanins, polyphenols and associated enzymes in Euphorbia heterophylla L. seedlings explants cultures. Journal of Plant Biochemistry and Biotechnology, Paris, v. 3, p. 69-72, 1994.

RAMAGE, C. M.; WILLIAMS, R. R. Mineral nutrition and plant morphogenesis. In Vitro Cellular Development Biology-Plant, Gaithersburg, v. 38, n. 2, p. 116-124, 2002.

RIBAS, A. L. Estudos sobre cultura de tecidos do maracujá amarelo (Passiflora edulis f. flavicarpa DEG.). 2000. Dissertação (Mestrado) - Universidade Federal do Paraná, Curitiba, 2000.

SAHER, S.; PIQUERAS, A.; HELLIN, E.; OLMOS, E. Hyperhidricity in micropropagated carnation shoot: the role of oxidative stress. Physiologia Plantarum, Denmark, v. 120, n. 1, p. 152-161, 2004.

SKOOG, F.; MILLER, C. O. Chemical regulation of growth and organ formation plant tissues culture in vitro. Symposia of the Society for Experimental Biology, Cambridge, v. 11, p. 118-140, 1957.

TRAN THANH VAN, M. Direct flower neoformation from superficial tissue of small explants of Nicotiana tabacum L. Planta, Berlin, v. 115, p. 87-92, 1973.

VAMSIDHARA, B. A.; HABEEB-MOHAMMEDA, B.; NATARAJC, D. C.; MADHUSUDANA-RAOC, D.; MULLANGI-RAMESHC. Antinociceptive activity of Euphorbia heterophylla roots. Fitoterapia, Milan, v. 71, p. 562-563, 2000. 
VIDAL, R. A.; MEROTTO JÚNIOR, A. Herbicidologia. Porto Alegre: Evangraf, 2001. 152 p.

VIDAL, R. A.; WINKLER, L. M. Resistência de plantas daninhas: seleção ou indução à mutação pelos herbicidas inibidores de acetolactato (ALS): pesticidas. Revista de Ecotoxicologia e Meio Ambiente, Curitiba, v. 12, p. 31-42, 2002.
WILSON, A. K. Euphorbia heterophylla: a review of distribution, importance and control. Tropical Pest Management, London, v. 27, n. 1, p. 32-38, 1981.

ZIV, M. In vitro acclimatization. In: AITKEN-CHRISTIE, J.; KOZAI, T.; LILA-SMITH, M. (Eds.). Automation and environmental control in plant tissue culture. Dordrecht: Kluwer Academic, 1995. p. 493-516. 